\title{
Effect of Organic Extractants on the Extraction of Rare Earth Elements from Sulphuric Acid Leach Liquor
}

\author{
Altansukh Batnasan*, Ariunbolor Narankhuu, Ariuntuya Battsengel, Kazutoshi \\ Haga, Atsushi Shibayama \\ Graduate School of International Resource Sciences, Akita University, 1-1, Tegata-gakuen-machi, Akita, 010- \\ 8502, Japan \\ "Corresponding author. Email: altansukh@gipc.akita-u.ac.jp
}

\begin{abstract}
In this study, the various organic extractants, namely D2EHPA, PC-88A, TBP, TBPP, TOA, and TOPO, were examined to extract REEs from sulphuric acid leach liquor of apatite ore. Extraction parameters including extractants type, the concentration of extractant, organic to aqueous phase ratio, and contact time were investigated. Stripping experiments were conducted using different concentrations (0.5-4 M) of hydrochloric acid. Results showed that the overall extraction of REEs into the PC-88 extractant were ranged between 20 and $35 \%$, while their extraction with other extractants did not exceed $20 \%$. Interestingly, heavy rare earth elements ( Tb, Dy, Er, and Y) were selectively extracted with D2EHPA when the light REEs extraction was lower than $5 \%$.
\end{abstract}

Keywords: Apatite, Rare earth elements, Leach liquor, Extractant, Solvent extraction

\section{INTRODUCTION}

REEs consisting of the 15 lanthanides and yttrium $(\mathrm{Y})$, scandium $(\mathrm{Sc})$ in the periodic table are relatively abundant in the earth's crust. Although they are typically dispersed and rarely occur in concentrated forms. Economic deposits of REEs in mining are bastnasite ( $\mathrm{La}, \mathrm{Ce}) \mathrm{FCO}_{3}$, monazite $(\mathrm{Ce}, \mathrm{La}, \mathrm{Y}$, Th) $\mathrm{PO}_{4}$, and xenotime $\mathrm{YPO}_{4}$, but more than 200 rare bearing minerals occur in the crust. One of the critical host minerals for REEs is apatite in igneous and metamorphic rocks [1-3]. The demand for REEs is increasing drastically with the development of electronics, communication, and energy technologies because of their unique physical, chemical, electrical, magnetic, and optical properties $[4,5]$. The hydrometallurgical process involving acid leaching and solvent extraction is the most common method of recovering rare earth elements from natural resources. Namely, REEs present in apatite are typically recovered using hydrochloric $(\mathrm{HCl})$, nitric
$\left(\mathrm{HNO}_{3}\right)$, and sulphuric acid $\left(\mathrm{H}_{2} \mathrm{SO}_{4}\right)$ leaching. REEs dissolution from apatite with $\mathrm{HNO}_{3}$ and $\mathrm{HCl}$ solution is more efficient than that with $\mathrm{H}_{2} \mathrm{SO}_{4}$ solution due to the formation of gypsum by-product [6-8]. Recovering REEs from leach liquor obtained by acid leaching is difficult due to their similar physical and chemical properties. Accordingly, many organic extractants, cation, and anion exchangers have been used to purify and separate REEs from aqueous leach liquors [9, 10]. Nowadays, the solvent extraction process has been widely used for separating REEs from the leach liquor using commercial extractants such as D2EHPA, HEHEHP, Versatic 10, TBP, and Aliquat 336 [11-13]. The essential parameters in leaching, extraction, and purification are needed to optimize to develop a highly efficient REEs recovery technique. On the other hand, optimizing a processing operation for recovering REEs from the natural ores could be an efficient way to improve the mining efficiency and reduce the environmental 
impact. To address this challenge, we have proposed a viable method to extract REEs from leach liquors obtained from sulphuric, nitric, and hydrochloric acid leaching of apatite ore using various organic extractants.

In this study, the extraction of REEs from sulphuric acid leach liquor of apatite ore using various organic extractants such as D2EHPA, PC88A, TBP, TBPP, TOA, and TOPO was discussed to determine the most suitable REEs extraction conditions.

\section{EXPERIMENTAL}

\subsection{Material and Reagents}

A sample received from apatite ore located in the south region of Mongolia was used in this study. The sample was crushed, milled, and sieved to collect specific size fractions from $<75$ to $250 \mu \mathrm{m}$. Particle size $-150+100 \mu \mathrm{m}$ was selected in leaching experiments presented in this study. The main mineral constituents in the apatite ore are fluorapatite $\left(\mathrm{Ca}_{10}\left(\mathrm{PO}_{4}\right)_{6} \mathrm{~F}_{2}\right)$ and phlogopite $\left(\mathrm{KMg}_{3}\left(\mathrm{Si}_{3} \mathrm{Al}\right) \mathrm{O}_{10} \mathrm{~F}_{2}\right)$, while the accompanying minerals are quartz $\left(\mathrm{SiO}_{2}\right)$, hematite $\left(\mathrm{Fe}_{2} \mathrm{O}_{3}\right)$, and celestine $\left(\mathrm{SrSO}_{4}\right)$ as determined by X-ray diffraction (XRD) analysis (Figure 1). The determined chemical composition of the apatite ore using both X-ray fluorescence (XRF) spectrometry, ZSX Series (Rigaku), and inductively coupled plasma optical emission spectrometer (ICPOES), SPS-5500 (Seiko Instruments Inc.) are summarized in Table 1.

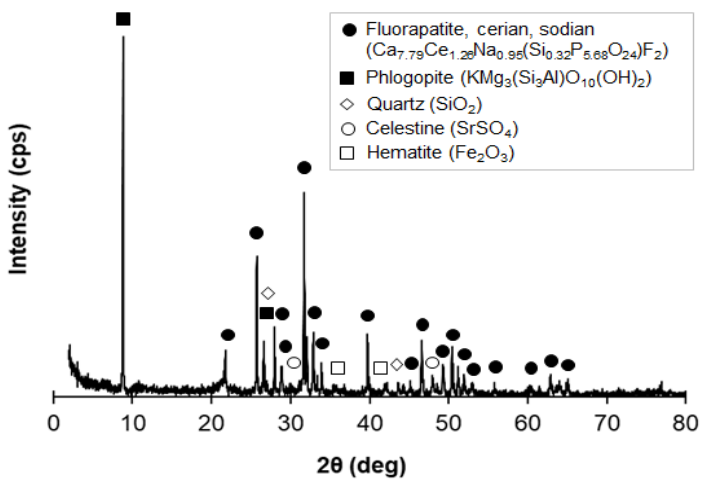

Figure 1. XRD pattern of apatite ore

Reagents grade chemicals such as sulphuric acid $\left(\mathrm{H}_{2} \mathrm{SO}_{4}\right)$, hydrochloric acid $(\mathrm{HCl})$, nitric acid $\left(\mathrm{HNO}_{3}\right)$ were used to dissolve REEs from the apatite ore. Several organic extractants, namely di-(2-ethylhexyl) phosphoric acid (D2EHPA), 2-ethylhexyl phosphonic acid mono-2-ethylhexyl ester (PC-88A), tributyl phosphate (TBP), tributyl phosphine (TBPP), trioctylamine (TOA), and trioctylphosphine oxide (TOPO), were used in the solvent extraction experiments to recover REEs from the leach liquors. The organic extractants were diluted with kerosene to the required concentrations for the extraction of REEs from acidic leach liquor. An automatic shaker (Almighty shaker, AW-2, AS ONE) and glass separatory funnels were used for REEs extraction and stripping experiments.

Table 1. Chemical composition of apatite ore, mass $\%$

\begin{tabular}{|c|c|c|c|c|c|c|c|c|c|}
\hline \multicolumn{10}{|c|}{ Rare earth elements (REEs) in the apatite ore } \\
\hline $\mathrm{La}$ & $\mathrm{Ce}$ & $\mathrm{Pr}$ & $\mathrm{Nd}$ & $\mathrm{Sm}$ & $\mathrm{Eu}$ & $\mathrm{Dy}$ & $\mathrm{Er}$ & $\mathrm{Y}$ \\
\hline 3.0 & 6.0 & 0.7 & 2.2 & 0.2 & 0.04 & 0.03 & 0.01 & 0.4 \\
\hline \multicolumn{10}{|c|}{ Accompanying elements } \\
\hline $\mathrm{Ca}$ & $\mathrm{P}$ & $\mathrm{Si}$ & $\mathrm{Fe}$ & $\mathrm{Al}$ & $\mathrm{Sr}$ & $\mathrm{Mg}$ & $\mathrm{Na}$ & $\mathrm{K}$ & $\mathrm{F}$ \\
\hline 24.0 & 8.9 & 7.3 & 4.2 & 2.2 & 1.5 & 0.5 & 0.3 & 0.3 & 3.2 \\
\hline
\end{tabular}

\subsection{Analysis}

Temperature and agitation speed (revolutions per minute, rpm) through the apatite dissolution in acid solutions were controlled by an automatic multiposition magnetic stirring hot plate, $\mathrm{HSH}-6 \mathrm{D} / \mathrm{As}$ One Corp/. A mechanical shaker [Almighty shaker AW-2, AS ONE] was used for extraction and stripping experiments. The components and content of various solid residues were determined by XRD, RINT2200/PC (Rigaku), and XRF, ZSX Primus II (Rigaku), respectively. Concentrations of elements in the aqueous phases obtained from acid leaching, extraction, and stripping were measured using ICPOES, SPS-5500 (Seiko Instruments Inc.). The $\mathrm{pH}$ levels of the aqueous phases were measured using the LAQUA pH meter, Horiba Scientific.

\subsection{Preparation of Leach Liquors}

Leach liquor of apatite ore was prepared by dissolving the pulverized ore sample with $-150+100$ $\mu \mathrm{m}$ in size with $\mathrm{H}_{2} \mathrm{SO}_{4}$ solution under the condition determined previously [14-16]: acid concentration of $1 \mathrm{M}$, solid to liquid phase ratio of $1: 50$, agitation speed of $500 \mathrm{rpm}$, leaching time of $1 \mathrm{~h}$ at ambient temperature $\left(22 \pm 3^{\circ} \mathrm{C}\right)$. After completed the leaching experiment, the leachate as leach liquor and solid residue were separated by a filtration process, and then the residue was washed with distilled water. The leach liquor prepared was used in further solvent extraction study for the REEs recovery.

\subsection{Extraction of REEs}

Solvent extraction study was performed using different organic extractants such as D2EHPA, PC88A, TBP, TBPP, TOA, and TOPO in kerosene. 
Various extraction conditions, particularly extractants type, extractant concentration, organic/aqueous phase ratio, and contact time, were examined.

The organic extractant and leach liquor were mixed at the volume ratio of $\mathrm{O}: \mathrm{A}=2: 1$ and shaken on a mechanical shaker (300 rpm, Almighty shaker AW2, AS ONE) at an ambient temperature for $20 \mathrm{~min}$ and then separated the 2 phases by a separation funnel. After phase separation, concentrations of REEs in the aqueous phase were determined using ICP-OES, and the concentrations of REEs extracted in the organic phase were calculated by mass balance. Then the extraction efficiencies of REEs in the organic phase were estimated using Equation (1).

$\mathrm{E} \%=\frac{\mathrm{C}_{\text {Initial }}-\mathrm{C}_{\text {finzl }}}{\mathrm{C}_{\text {initial }}} * 100$

Where; E\% represents the percentage of REEs extracted into the organic phase, $\mathrm{C}_{\text {initial }}$ concentration of $\mathrm{REE}$ in the leach liquor, $\mathrm{C}_{\text {final }}-$ remained REE's concentration in the aqueous phase (raffinate) after extracting REE into the organic phase.

\subsection{Stripping (Back Extraction) of Loaded REES}

Stripping of loaded REEs into D2EHPA organic phase was carried out using various concentrations of hydrochloric acid $(\mathrm{HCl})$ ranging from 0.5 to $4 \mathrm{M}$ at ambient temperature for $20 \mathrm{~min}$. The ratio of loaded organic phase to $\mathrm{HCl}$ as strip solution was maintained at $1: 2$ for each experiment.

\section{RESULT AND DISCUSSIONS}

\subsection{Preparation of Leach Liquor}

The dissolution of main REEs from the apatite ore in $1 \mathrm{M} \mathrm{H}_{2} \mathrm{SO}_{4}$ solution is presented in Figure 2. The result showed that the dissolution efficiencies of heavy rare earth elements (HREEs), especially Dy, Er, and Y, are slightly high than the dissolution of light rare earth elements (LREEs), namely La, Ce, Pr, and $\mathrm{Nd}$.

It was evaluated that the average dissolution efficiencies of LREEs (La, Ce, Pr, Nd, and Eu) and HREEs (Dy, Er, and Y) from the apatite with $1 \mathrm{M}$ $\mathrm{H}_{2} \mathrm{SO}_{4}$ were $86.0 \%$ and $92.6 \%$, respectively. It implies that about 14\% LREEs and $7.4 \%$ HREEs were lost with the leach residue due to the formation of gypsum. The REEs dissolution and gypsum formation through the apatite leaching in $\mathrm{H}_{2} \mathrm{SO}_{4}$ solution can be represented as follows $[15,16,17]$ :

$$
\begin{aligned}
& \mathrm{REE}^{\mathrm{a}+}+\mathrm{SO}_{4}^{2-}=\mathrm{REE}_{2}\left(\mathrm{SO}_{4}\right)_{3} \\
& \mathrm{Ca}_{10}\left(\mathrm{PO}_{4}\right)_{6} \mathrm{~F}_{2}+10 \mathrm{H}_{2} \mathrm{SO}_{4}+\mathrm{xH}_{2} \mathrm{O}=6 \mathrm{H}_{2} \mathrm{PO}_{4}+ \\
& 10 \mathrm{CaSO}_{4} \cdot \mathrm{xH}_{2} \mathrm{O}+2 \mathrm{HF}
\end{aligned}
$$

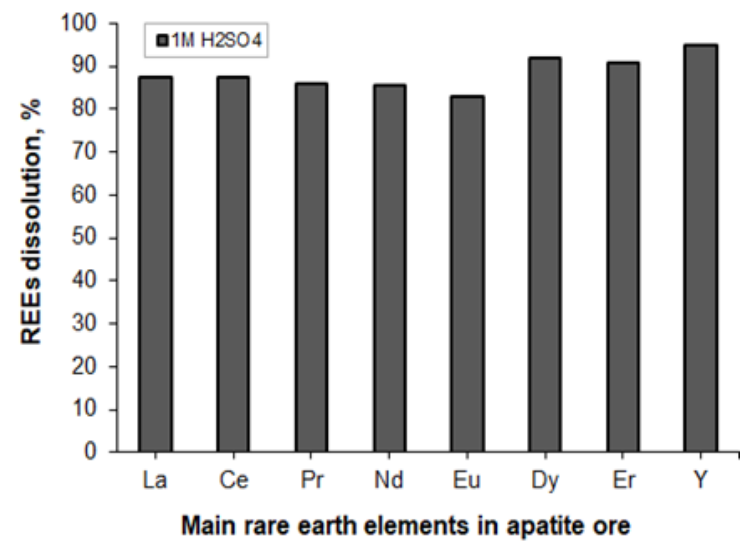

Figure 2. The tendency of REEs dissolution from apatite ore in $\mathrm{H}_{2} \mathrm{SO}_{4}$ solution (acid concentration: 1 $\mathrm{M}$, particle size: $-150+100 \mu \mathrm{m}, \mathrm{S}$ : L phase ratio $=1: 50,500 \mathrm{rpm}$, leaching time: $1 \mathrm{~h}$, leaching temperature: $22 \pm 3^{\circ} \mathrm{C}$ )

Table 2 shows the contents of REEs and accompanying elements in the prepared sulphuric acid leach liquor.

Table 2. Chemical contents of the leach liquor

\begin{tabular}{|c|c|c|c|c|c|}
\hline LREE & $\begin{array}{c}\text { Conc } \\
(\mathbf{p p m})\end{array}$ & HREE & $\begin{array}{c}\text { Conc } \\
(\mathbf{p p m})\end{array}$ & $\begin{array}{c}\text { Other } \\
\text { elements }\end{array}$ & $\begin{array}{c}\text { Conc } \\
(\mathbf{p p m})\end{array}$ \\
\hline La & 798.2 & $\mathrm{~Tb}$ & 3.6 & $\mathrm{Na}$ & 111.5 \\
\hline $\mathbf{C e}$ & 1849.4 & $\mathrm{Dy}$ & 15.7 & $\mathrm{~K}$ & 39.4 \\
\hline $\mathbf{P r}$ & 160.2 & $\mathrm{Ho}$ & 1.1 & $\mathrm{Ca}$ & 1201.7 \\
\hline $\mathbf{N d}$ & 592.7 & $\mathrm{Er}$ & 7.0 & $\mathrm{Sr}$ & 116.1 \\
\hline Sm & 74.3 & $\mathrm{Lu}$ & 2.8 & $\mathrm{Fe}$ & 54.3 \\
\hline Eu & 9.5 & $\mathrm{Y}$ & 83.4 & $\mathrm{Al}$ & 203.3 \\
\hline Total & $\mathbf{3 4 8 4 . 3}$ & & $\mathbf{1 1 3 . 6}$ & & $\mathbf{1 7 2 6 . 3}$ \\
\hline
\end{tabular}

\subsection{Solvent Extraction Study}

Various extraction parameters, viz. extractants type, extractant concentration, organic to aqueous phase ratio, and contact time were examined and optimized. Furthermore, influences of the parameters on the REEs extraction from the sulphuric acid leach liquor of apatite ore were discussed below.

\subsubsection{Influence of the Extractant Type}

Figure 3 shows a comparison of extraction efficiencies of REEs from sulphuric acid leach liquor of apatite into various organic extractants, namely, D2EPHA, TBP, TPP, TOA, TOPO, and PC-88A under the same extraction condition. 
The results indicated that the extraction efficiencies of $\mathrm{Tb}, \mathrm{Dy}, \mathrm{Er}$, and $\mathrm{Y}$ as HREEs into D2EPHA were $36.2,55.0,77.0$, and $88.3 \%$, respectively, while the efficiencies of LREEs ( $\mathrm{La}, \mathrm{Ce}$, $\mathrm{Pr}, \mathrm{Nd}, \mathrm{Sm}$ ) extraction were lower than 5\%. It implies that LREEs and HREEs could be extracted selectively from the leach liquor with D2EPHA in sulphuric acid media. Whereas a selective extraction of LREEs and HREEs was not achieved with PC-AA when their extraction efficiencies were between $20 \%$ and $35 \%$. In comparison, the extraction efficiencies lower than $15 \%$ and $22 \%$ were obtained for LREEs and HREEs with TBP, TBPP, TOA, and TOPO, respectively. It indicates that these extractants were not selective and inefficient in extracting REEs from the leach liquor.

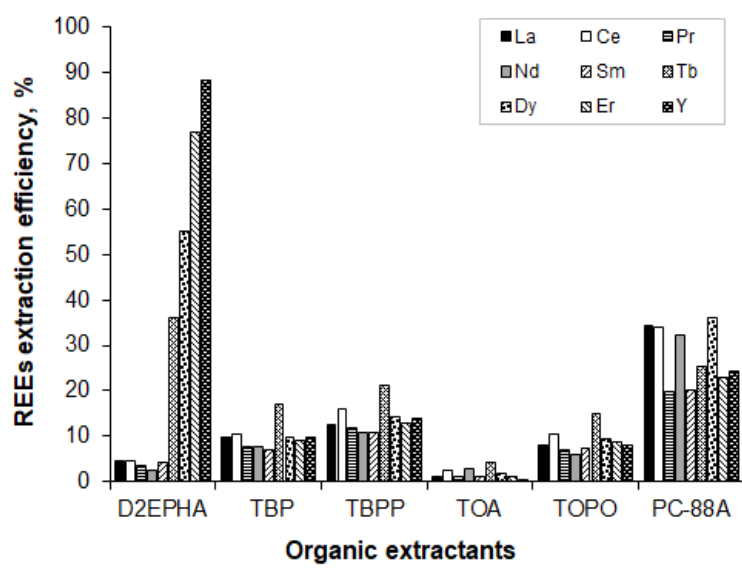

Figure 3. REEs extraction efficiencies as a function of the influence of extractants $(\mathrm{O}: \mathrm{A}$ ratio $=1: 2, \mathrm{pH} 1$ (initial), extractant: $20 \mathrm{vol} \%, 300 \mathrm{rpm}$, at $20^{\circ} \mathrm{C}$ for $20 \mathrm{~min}$ )

The extraction of REEs from the leach liquor into the organic extractants is generally expressed as below:

$\mathrm{REE}_{\text {(aq) }}^{\mathrm{a+}}+3(\mathrm{HL})_{2 \text { (org) }}=\mathrm{REE}\left(\mathrm{HL}_{2}\right)_{a}+3 \mathrm{H}^{+}$

Where: (HL) 2 (org) is organic extractant (D2EHPA, PC$88 \mathrm{~A}$, TBP etc.)

A comparison of REEs extraction with various extractants implies that the molecular structure of organic extractants could correspond with the efficiency of REEs extraction. Because D2EHPA and PC-88A, which were relatively higher REEs extraction, have closer molecular structures than other extractants [17]. A phosphorus $(\mathrm{P})$ atom in D2EHPA is single bonded to two oxygen atoms and a hydroxyl (-OH) group and double-bonded with an oxygen atom. In comparison, the $\mathrm{P}$ in $\mathrm{PC}-88 \mathrm{~A}$ is single bonded to one oxygen atom (Figure 4 ).<smiles>CCCCC(CC)COP(=O)(O)OCC(CC)CCCC</smiles>

D2EHPA $\left(\mathrm{C}_{16} \mathrm{H}_{35} \mathrm{O}_{4} \mathrm{P}\right)$

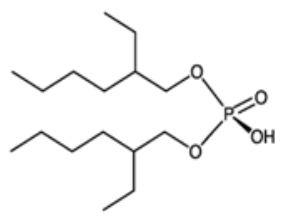

$\mathrm{PC}-88 \mathrm{~A}\left(\mathrm{C}_{16} \mathrm{H}_{35} \mathrm{O}_{3} \mathrm{P}\right)$
Figure 4. Molecular structure of D2EHPA and PC$88 \mathrm{~A}$

\subsubsection{Influence of D2EHPA Concentration}

The concentration of D2EHPA as an organic extractant was varied from 20 to 100 vol. $\%$ by dilution with the kerosene. Figure 5 shows that the extraction of REEs increases with an increase in the D2EHPA concentration at the same condition.

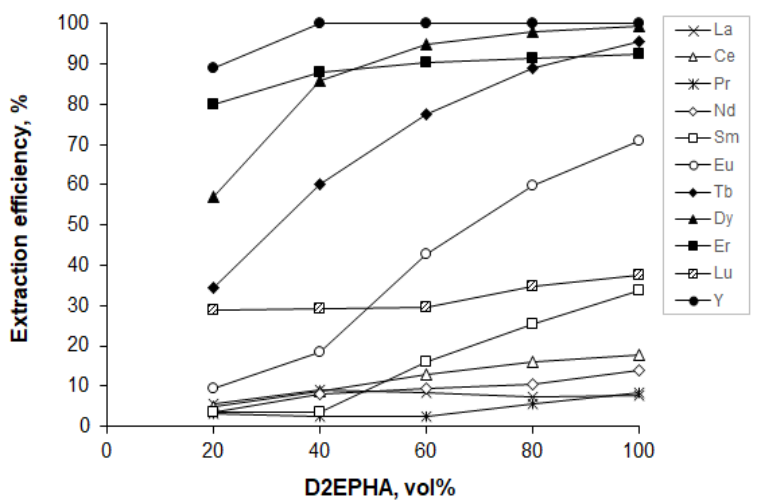

Figure 5. REEs extraction as a function of D2EHPA concentration (O:A ratio=1:2, $\mathrm{pH} 1$ (initial),

D2EHPA: $20-100$ vol. $\%, 300 \mathrm{rpm}$, at $20^{\circ} \mathrm{C}$ for 20 $\min$ )

Results indicate that the maximum extraction efficiencies of REEs except $\mathrm{Y}$ were achieved with 100 vol\% D2EHPA. On the contrary, over $99 \% \mathrm{Y}$ was extracted into $60 \mathrm{vol} \%$ D2EHPA. It was found that an increase in the efficiency of REEs extraction could be correlated with a decrease in ionic radii of hydrated ions.

\subsubsection{Influence of Organic-aqueous Phase Ratio}

The extraction efficiencies of REEs from leach liquor depend significantly on the organic to aqueous $(\mathrm{O} / \mathrm{A})$ phase ratios, as shown in Figure 6 . The extraction rates of $\mathrm{La}, \mathrm{Ce}, \mathrm{Pr}$, and $\mathrm{Nd}$ from leach liquor were constant through the different $\mathrm{O} / \mathrm{A}$ ratio conditions. With decreasing the O/A ratio from 5:1 to $1: 4$, the extraction of $\mathrm{Sm}$ and $\mathrm{Eu}$ was reduced drastically, while the extraction of Tb, Dy, Er, Lu and 
$\mathrm{Y}$ as HREEs was slightly decreased under the conditions. Results indicate that the LREEs and HREEs can selectively separate using the D2EHPA extractant because higher extraction efficiencies were achieved for Tb, Dy, Er, Lu and Y when the organic phase ratio is higher than the aqueous phase.

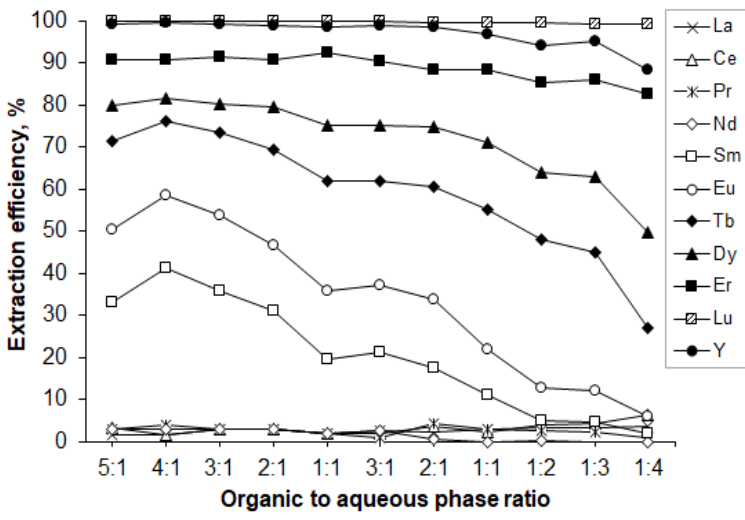

Figure 6. REEs extraction as a function of $\mathrm{O} / \mathrm{A}$ phase ratios (O:A ratio=5:1-1:4, $\mathrm{pH} 1$ (initial), D2EHPA:

$60 \mathrm{vol} \%, 300 \mathrm{rpm}$, at $20^{\circ} \mathrm{C}$ for $20 \mathrm{~min}$ )

The O/A phase ratio of 5:1 was selected as an optimal condition for further study.

\subsubsection{Influence of Contact Time}

The extraction of all REEs from the leach liquor has the same tendency depending on the contact time (Figure 7). Specifically, the extraction of REEs increases drastically with an increase in contact time from 1 to 5 minutes, but the further increase in the time over 10 minutes has no apparent influence on the REEs extraction. Hence, the contact time of 10 min chosen was an optimum contact time.

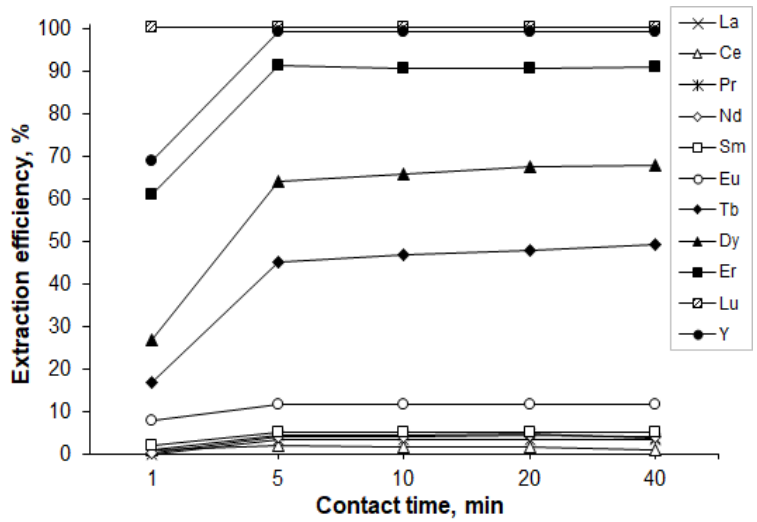

Figure 7. REEs extraction as a function of contact time (O:A ratio=5:1, $\mathrm{pH} 1$ (initial), D2EHPA: 60 vol\%, $300 \mathrm{rpm}$, at $20^{\circ} \mathrm{C}$ for $1-40 \mathrm{~min}$ )

\subsubsection{Stripping of loaded REEs}

The stripping percentages of LREEs and HREEs from the loaded organic phase (D2EHPA) showed different tendencies (Figure 8). Generally, stripping of REEs loaded into extractants can be represented as below.

$2 \mathrm{REE}\left(\mathrm{HL}_{2}\right)_{3}+3 \mathrm{H}_{2} \mathrm{SO}_{4}=\mathrm{REE}_{2}\left(\mathrm{SO}_{4}\right)_{3}+6(\mathrm{HL})_{2}$

Moreover, the stripping percentage of HREEs such as Tb, Dy, Er, and Y increases drastically with increasing the $\mathrm{HCl}$ concentration from $0.5 \mathrm{M}$ to $4 \mathrm{M}$. The maximum stripping percentages of $75.2 \%$, $22.6 \%, 56.3 \%$, and $51.1 \%$ were achieved for $\mathrm{Tb}$, Dy, $\mathrm{Er}$, and $\mathrm{Y}$ with $4 \mathrm{M} \mathrm{HCl}$ strip solution.

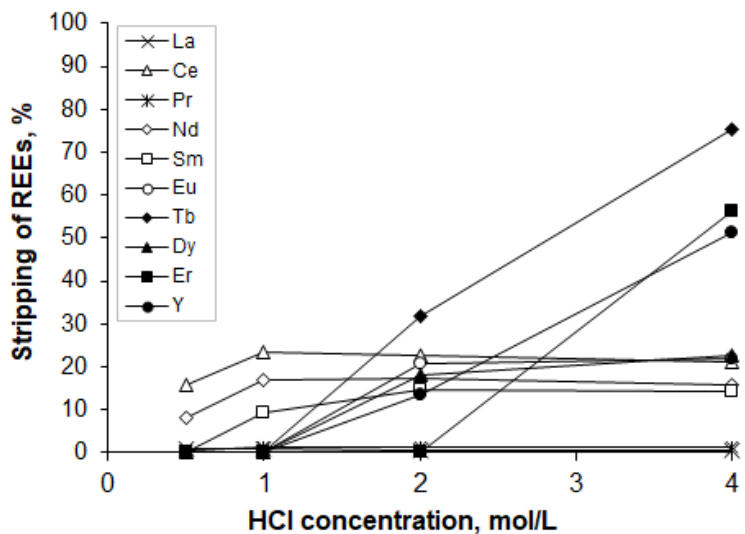

Figure 8. REEs stripping as a function of $\mathrm{HCl}$ concentration $(\mathrm{A} / \mathrm{O}$ ratio $=1: 2, \mathrm{HCl}$ concentration: $0.5-4 \mathrm{M}, 300 \mathrm{rpm}$, at $20^{\circ} \mathrm{C}$ for $20 \mathrm{~min}$ )

For LREEs loaded into D2EHPA, La, Ce, Pr, and $\mathrm{Nd}$ were stripped sufficiently by $1 \mathrm{M} \mathrm{HCl}$ and their stripping percentages were normalized to increase the $\mathrm{HCl}$ concentration further. On the other hand, the maximum stripping percentage for $\mathrm{Sm}$ and $\mathrm{Eu}$ achieved was $14.7 \%$ and $22.0 \%$, respectively, at $2 \mathrm{M}$ $\mathrm{HCl}$ solution. It indicates that HREEs could be stripped efficiently and selectively from the loaded D2EHPA than LREEs. A further study is necessary to strip LREEs completely from the loaded organic phase.

\section{CONCLUSION}

The recovery of REEs from apatite ore using sulphuric acid leaching, solvent extraction, and stripping was investigated in this study. The results obtained from the combined technique are summarized as follows.

* The vast majority of REEs $(87.4 \%$ La, $87.3 \%$ Ce, $86.1 \%$ Pr, $85.6 \%$ Nd, $82.8 \%$ Eu, $92.0 \%$ Dy, 
91.0\% $\mathrm{Er}$, and $94.8 \% \mathrm{Y}$ ) were dissolved from the apatite ore in a diluted $\mathrm{H}_{2} \mathrm{SO}_{4}$ solution under the previously determined conditions.

* The dissolution efficiencies of HREEs including Dy, Er, and Y were 4-5\% higher than the dissolution of LREEs ( $\mathrm{La}, \mathrm{Ce}, \mathrm{Pr}, \mathrm{Nd}$, and $\mathrm{Eu}$ )

* It was revealed that the loss of REEs from apatite ore in $\mathrm{H}_{2} \mathrm{SO}_{4}$ solution is related to the formation of gypsum $\left(\mathrm{CaSO}_{4} \cdot \mathrm{xH}_{2} \mathrm{O}\right)$ as a passivation layer on the apatite surface.

* D2EHPA has high efficiency and high selectivity for extracting HREEs (Tb, Dy, Er and Y) from sulphuric acid leach liquor compared to the other extractants.

* Stripping yields of HREEs (Tb, Dy, and Y) were higher percentage (50-75\%) with a $4 \mathrm{M}$ hydrochloric acid $(\mathrm{HCl})$ solution.

A propose hydrometallurgical technique is a possibility for REEs recovery from apatite ores.

\section{ACKNOWLEDGMENTS}

This study was supported by the Program for Leading School ("Only-one" Category) and KAKENHI (Grant number: JP16K18330) from Japan Society for the Promotion of Science (MEXT Grants).

\section{REFERENCES}

[1] Krishnamurthy N., Gupta C.K., (2016) Extractive metallurgy of rare earths. 2nd Edition. (CRC press).

[2] EuRare, (2017) What are Rare Earth Elements? http://www.eurare.org/ RareEarthElements.html (Accessed 15 June 2020).

[3] Habashi F., (2013) Extractive metallurgy of rare earths. Journal of Canadian Metallurgical. Quarterly, Vol.52, 224-233. DOI: 10.1179/1879139513Y.0000000081

[4] Kanazawa Y., Kamitani M., (2016) Rare earth minerals and resources in the world. Journal of Alloys and Compounds, Vol. 408-412, 13391343. DOI: 10.1016/j.jallcom. 2005.04.033

[5] Goodenough K.M., Wall F., Merriman D., (2018) The rare earth elements: demand, global resources, and challenges for resourcing future generations. Natural Resources Research, Vol. 27(2), 201-216. DOI: 10.1007/s11053-0179336-5
[6] Jha M.K., Kumari A., Panda R., Kumar J.R., Yoo K., Lee J.Y., (2016) Review on hydrometallurgical recovery of rare earth metals. Hydrometallurgy., Vol. 165(1), 2-26. DOI: 10.1016/j.hydromet.2016.01.035

[7] Habashi F., (1985) The recovery of the lanthanides from phosphate rock. Journal of Chemical Technology and Biotechnology, Vol. 35, 5-14. DOI: $10.1002 /$ jctb.5040350103

[8] Li Z., Xie Z., Deng J., He D., Zhao H., Liang H., (2021) Leaching Kinetics of Rare Earth Elements in Phosphoric Acid from Phosphate Rock. Metals, Vol. 11, 239. DOI: 10.3390/met11020239

[9] Zhang J., Zhao B., Schreiner B., (2016) Separation Hydrometallurgy of Rare Earth Elements. Springer International Publishing, Switzerland. DOI: 10.1007/978-3-319-282350_1

[10] Huang X., Dong J., Wang L., Feng Z., Xue Q., Meng X., (2017) Selective recovery of rare earth elements from ion-adsorption rare earth element ores by stepwise extraction with $\mathrm{HEH}(\mathrm{EHP})$ and HDEHP. Green Chemistry, Vol. 19(5), 13451352. DOI: $10.1039 / \mathrm{C} 6 \mathrm{GC} 03388$ A

[11] Xie F., Zhang T.A., Dreisinger D., Doyle F., (2014) A critical review on solvent extraction of rare earths from aqueous solutions. Journal of Minerals Engineering, Vol. 56, 10-28. DOI: 10.1016/j.mineng.2013.10.021

[12] Yudaev P.A., Kolpinskaya N.A., Chistyakov E.M., (2021) Organophosphorous extractants for metals. Hydrometallurgy., Vol. 201, 105558. DOI: $10.1016 /$ j.hydromet.2021.105558

[13] Asadollahzadeh M., Torkaman R., TorabMostaedi M., (2020) Extraction and Separation of Rare Earth Elements by Adsorption Approaches: Current Status and Future Trends. Separation and Purification Reviews, 1-27. DOI: 10.1080/15422119.2020.1792930

[14] Ariunbolor N., (2015) Recovery of Rare Earth Elements (REEs) from Apatite Ore by Hydrometallurgical Processing. Master thesis, Akita University, Japan.

[15] Ariuntuya B., (2018) Recovery of Rare Earth Elements from Apatite Ores by Hydrometallurgical Process. Ph.D thesis, Akita University, Japan. 
[16] Battsengel A., Batnasan A., Narankhuu A., Haga K., Watanabe Y., Shibayama A., (2018) Recovery of light and heavy rare earth elements from apatite ore using sulphuric acid leaching, solvent extraction and precipitation. Hydrometallurgy, Vol. 179, 100-109. DOI: $\underline{10.1016 / j . h y d r o m e t .2018 .05 .024}$

[17] Rydberg J., Cox M., Musikas C., Choppin G.R., (2004) Solvent Extraction Principles and Practice. 2nd Edition, Marcel Dekker, Inc., New York, 339-365. DOI: 10.1201/9780203021460 